\title{
PSYCHOLOGICAL FACTORS OF ETHNIC EXTREMISM IN MUSLIM YOUTH
}

\author{
Elena Chebotareva \\ Peoples Friendship University of Russia \\ chebotarevy@yandex.ru
}

DOI:10.5901/mjss.2014.v5n22p140

\begin{abstract}
The aim of the research was to reveal the correlations between the extreme forms of ethnic identity and some personal traits involved in intercultural communication. Also the task of the research was to analyze cultural specificity in ethnic extremism manifestations at Muslim youth.420 young people from 6 regions of the world (Russia, China, South America, Africa, the Middle East and Central Asia) took part in the research; among them 81 people from the Middle East countries and 60 - from the former soviet Central Asian countries. 14 psychodiagnostic techniques were used to measure various personal features associated with cross-cultural communication. The technique "Types of ethnic identity" (G.U.Soldatova, S.V.Ryzhova) was applied for diagnosing the types of identity with different degrees of ethnic tolerance that were marked on a wide range of ethnocentrism scale. We used statistical techniques: Kruskall Wallis test, Multiple range tests, multifactorial dispersive analysis, Spearman's rank correlation coefficient. The comparative analysis of young people, who responded high scores in extreme form of ethnic identity (ethnic bigotry or fanaticism) (147) and those who showed low levels of ethnic bigotry (134), revealed that persons inclined to ethnic bigotry were less tolerant not only for other ethnic group, but to any manifestations of individuality and to other social groups: they were more egocentric, not able to adjust themselves to different situations and people. They couldn't control their negative emotions and were less able to recognize the other's emotions by facial expression (especially fear, disgust and contempt). Also they were not sure in the world controllability; are less flexible in their activity control. Correlation analysis on general sample showed that ethnic bigotry inversely correlated with the life purposes awareness, internal locus of control, positive self - image, social and emotional intelligence, flexibility in the activity regulation. Positive correlation of ethnic extremis with disbelieve in the world controllability, egocentrism and apartness in interpersonal relations were revealed. Correlation analysis in Arab and Central Asian two subsamples showed some specific relations of ethnic bigotry and personal features. So, we can conclude that generally ethnic extremism correlates with rather controversial and conflict styles of self-realization and communication. Young people with extreme attitude toward other nations clearly realize their life goals, but they don't believe in their approachability and don't have enough abilities to interact with other people feeling the apartness in their personal interaction. The styles of interethnic communication of young representatives of different Muslim nations have some common features with the representatives of other nations, and have some specific features as well. Arab youth ethnic extremism correlates mostly with social stereotypes and hostility to other social groups, and Central Asian youth extremism correlates with intolerance to the other people individuality manifestation. Personal resources for the ethnic extremism reduction could be - for Arab people - their self - control in emotions and activity; and for the Central Asian people - concentration on their life goals. The research was supported by the Russian Humanitarian Science Foundation, project № 13-06-00673.
\end{abstract}

Keywords: Ethnic Identity, Ethnic Extremism, Ethnic Bigotry, Fanaticism, Intercultural Communication, Ethnic Tolerance, Ethnocentrism.

\section{Introduction}

Globalization processes taking place in the modern world, in addition to a large number of positive effects have some negative trends. In particular, the blurring of ethnic boundaries leads to the growth of national consciousness among the population up to its extreme manifestations. Intensification of intercultural contacts not only enriches the interacting cultures mutually, but also leads to an intensification of ethnic conflicts, to the growing of ethnic fanaticism manifestations and interethnic conflicts fomenting.

Ethnic extremism and fanaticism are often discussed in close conjunction with religious fanaticism; it is assumed that differences in religious persuasions are the main factors of the ethnic conflicts. This has led some to the conclusion that ethnic conflicts may be an inevitable result of intensive intercultural interaction.

In the modern world terrorism has become associated primarily with the Muslim religion. (Franz, 2007). The attacks committed by a tiny number of young Muslims cause the stigmatization of young Muslims around the world (Franz, 2007; 
Mythen, G., Walklate, S. \& Khan, F., 2009; Mcdonald, 2011). "The West has stereotyped Islam as a strange religion, completely different from Christianity or Judaism" (Cesari, 2002). Young Muslims have been the object of ideological struggle between the security, developing methods terrorism combating and terrorist recruiters. Also in recent times appears the information on the involvement of representatives of other religions in Muslim terrorist organizations.

In this regard, for psychologists the personal characteristics of young people who are prone to ethnic extremism are of particular importance. It is also important to research into the role of personality factors, religion, and social situation in the radicalization of ethnic attitudes of young people.

Extremism in interethnic relations we consider in the context of John Berry's theory of intercultural strategies. Berry understood the strategy of intercultural interaction as the link between attitudes and actual behavior (Berry, 1997). Numerous empirical studies have shown a relationship between acculturation strategies and styles of ethnic identity (Sumner, 1906). Berry allocated the types of ethnic identity with different quality and degree of ethnic tolerance on the basis of a wide range of ethnocentrism scale, ranging from identity denial when negativity and intolerance towards one's own ethnic group are fixed, and ending national fanaticism - the apotheosis of intolerance and a higher degree of negativity towards other ethnic groups.

Berry (1997) considered integration, wherein minority representatives harmoniously combine positive attitudes toward their own culture and dominant community. The assimilation (abandoning of the traditional cultures to strengthen ties with the dominant culture) and the separation (avoidance of the ties with larger society) are considered less positive strategies. The most destructive strategy, according Berry, is the marginalization (lack of adherence to any culture). The extreme forms of ethnocentrism is associated with religious fanaticism and racism and lead to violence and aggression (Saressalo, 1977).

On the basis of Berry's theory G.U. Soldatova and S.V. Ryzhova developed the typology and technique for assessing the ethnic identity types. They allocated the following types: Ethnic nihilism - removing from one's own ethnic groups and looking for social ties not on ethnic criteria; Ethnic indifference - ethnic identity blurring , irrelevance of the ethnicity; Positive ethnic identity - optimal balance of tolerance towards one's own and other ethnic groups; Ethnic egoism - recognition of own nation's right to solve problems for the "foreign" account; Ethnic isolationism - belief in one's nation superiority and xenophobia; Ethnic bigotry (fanaticism) suggesting the willingness to go all lengths for the sake of ethnic interests, denying the other nations rights to use any resources and social privileges, recognition of the priority of ethnic rights over human rights, excuse of any sacrifice in the struggle for own nation well-being.

Thus, psychology already formed certain ideas about the nature of ethnic extremism and fanaticism. But to optimize crosscultural contacts and reduce ethnic conflict it is necessary to identify cross-cultural features of ethnic extremism manifestations, as well as to reveal their personal and social factors.

\section{Method}

\section{Participants}

The sample included 420 students of different Russian universities from 5 regions of the world: Russia (69) South East Asia (80), Africa (60), South America (69), The Middle East (81), Central Asia (60) from 50 countries. The ages of the participants were $18-25$ years old, the mean age - 21.3 years old. Among the participants were 188 boys and 162 girls. Religious affiliation of the subjects: 123 - Christians, 152 Muslims, 75 Buddhists, 70 persons didn't report their religious affiliation.

\section{Materials}

Personal Information Form: This form was consisted of questions about gender, age, country of origin, university, religion.

The technique "Types of ethnic identity" (G.U.Soldatova, S.V.Ryzhova). This technique allows the diagnosis of ethnic identity and its transformation in the context of the ethnic interaction. The questionnaire contains six scales that correspond to the types of ethnic identity, described above. (Soldatova \& Shaygerova (Ed.), 2008)

For investigating personal factors of ethnic identity types we used the techniques for diagnosing different personal qualities involved in intercultural communication (Chebotareva, 2012-2014, Novikova \& Ibadova, 2009, Novikova, 2010 )

"Indicator of Stress Overcoming Strategies" (D. Amirhan) measures the severity of strategies: problem solving, searching for social support, avoiding problems ( ignoring them). (Yaltonsky \& Sirota, 1996). 
"Test of the Life Meanings Orientations" (D.A.Leontev) is an adapted version of " Purpose-in-Life Test" (PIL) (Crumbaugh, Maholick). The test assesses the overall meaningfulness of life, and also contains five subscales, reflecting the components of it. The subscales conditionally are divided into two groups. The first group reveal proper life meaning orientations: the goals in life (the future), the richness of life (the present) and satisfaction with self-realization (the past). The second group of scales is devoted to internal locus of control: one is about general philosophical belief that control is possible, and the second is about the belief in the person's own ability to exercise such a control (self-image). (Leontiev, 2000).

"Scale of base convictions" (R. Janov-Bulman) The technique was developed in the framework of the cognitive concept of the base beliefs. In accordance with it one of the basic sensations of a normal person is a healthy sense of security. For $R$. Janov-Bulman, it is based on three categories of base beliefs that make up the core of our subjective world: belief that the world is good rather than evil; belief that the world is full of meaning; belief in the value of one's own "l". This method identifies eight categories of beliefs: benevolence of world, benevolence of people, justice of the world, control over the world, randomness of life events, self-worth, self-control, luckiness. (Soldatova \& Shaygerova (Ed.), 2003)

"Scale of social distance" (E. Bogardus) in modification of V.N. Pavlenko and S.A. Taglin. In this modification, the subjects were asked to choose from the list of all possible social roles, which they agreed to provide the typical representatives of particular ethnic groups. We offered to the students to estimate their desired distance with representatives of all the studied regions. (Stefanenko, 2006).

"Who am I ?" - Twenty Statements Attitude Test (M. Kun, T. Macpartlend) we used for investigating the qualitative characteristics of personal identity. It is non-standardized self-report version. The respondents had within 12 minutes to give twenty different answers to the question: "Who am I?". The responses received were processed using content analysis. (Burlarchuk \& Morozov, 1999).

"Measurement of social intelligence" (J. Guilford) diagnoses four abilities, namely the ability to foresee the consequences of the behavior; understanding non-verbal communication; understanding verbal expression; holistic understanding of the interpersonal situations dynamics.

"Questionnaire of emotional intelligence" (D.V. Ljusin) measures the emotional intelligence (EI) which is interpreted as the ability to understand own and other people's emotions and to regulate own and other people's emotions. (Lusin \& Ushakov (Ed.), 2004).

"Gnosis Facialis Foto" (J. Merten, J. Spang) consists of 28 pictures, which show the following emotional states: joy, fear, disgust, surprise, anger, sadness / grief, contempt. The photos show the male (14) and female (14) Caucasians. Each emotion was represented by 4 photos (2 male, 2 female photos). (Bezmenov \& Belovol, 2007).

"Style of self-control" (V.I. Morosanova). The statements of the questionnaire are included in the six scales allocated in accordance with the basic regulatory processes: planning, modeling, programming, the results assessment, and personal regulatory traits: flexibility and independence. (Morosanova, 2004).

Adaptation (A.I. Krupnov) Five scales of the test reflect certain problems and difficulties in the foreign students adaptation (associated with the implementation of sociability, confidence; severity asthenic emotions, inability to regulate them, the strength of feelings of nostalgia and alienation). In general, these scales reflect the degree of disadaptation. Last scale adaptability - reflects a person's willingness to interact constructively with the new environment. (Chebotareva, 2012)

Person's adaptation to the New Social and Cultural environment (L.V. Yankovsky , T.G.Stefanenko, M.S.Panova) The technique includes six scales: the first three of which (Satisfaction, Interactivity, Conformity) show quite "positive" indicators of intercultural adaptation, the following three (Depressiveness, Nostalgia, Alienation) - certain problems in adapting (Sonin V.A., 2004).

Tolerance Index (G.U.Soldatova, O.A.Kravtsova, O.E. Hukhlaev) helps to determine the overall level of tolerance and the degree of ethnic, social tolerance and the tolerance as personality trait (Pochebut, 2005).

"Diagnostics of the General Communicative Tolerance" (V.V. Bojko). The questionnaire items are grouped into nine scales: Rejection or misunderstanding of other persons' identity; Using oneself as a standard when assessing the behavior and way of thinking of other people; Categoricity or conservatism in the estimates of other people; Inability to hide or smooth over bad feelings when faced with some uncommunicative characteristics of the partners; Desire to change, reeducate the partners; Desire to fit partners for themselves, to make them "convenient"; Inability to forgive the others' mistakes, clumsiness, unintentionally caused trouble; Intolerance to physical or mental discomfort caused by the other people; Inability to adapt to the character, habits and desires of others. (Soldatova \& Shaygerova (Ed.), 2008). 
We used statistical techniques: Mann — Whitney U-test, Spearman's rank correlation coefficient.

\section{Procedure}

The procedure of the research was approved by the Department of Social and Differential Psychology of Peoples' Friendship University of Russia (PFUR). All the questionnaires were translated into English, French, Spanish, Arabic and Chinese, the translated versions were pre-tested. Each subject was offered questionnaires in their native language (or in the language, which he/she use since their childhood). The survey was conducted personally by PFUR psychology students among their compatriots studying in various Russian universities. Each test was performed during 3-5 meetings, 30 minutes each.

\section{Results}

At the first stage of the data analysis the entire sample was divided into three groups based on the level of diagnosed ethnic fanaticism. The group with high levels of ethnic fanaticism included 134 students, a group with medium level -- 138, and with low level - 148. Next, we conducted a comparative analysis of students with high and low level of ethnic fanaticism ( $p=$ $0.000000 \ldots)$.

Finding of differences between students with high and low levels of ethnic fanaticism

We have found statistically significant differences in severity of all types of cross-cultural interaction. Students with low fanaticism showed higher level of positive ethnic identity $(p=0,02)$. Students with higher level of ethic fanaticism showed higher levels of all studied deviations in ethnic identity: ethnic nigilizm $(p=0,03)$, ethnic indifference $(p=0,05)$, ethnic egoism $(p=0,000000 \ldots)$, ethnic isolation $(p=0,000000 \ldots)$.

Students with high fanaticism showed less willingness to cooperate with other ethnic groups representatives $(p=0,05)$, especially great distance they felt with the representatives of Africa $(p=0,001)$ and Central Asia $(p=0,001)$.

Significant differences were found between these groups in the general level of communicative tolerance, as well as in many individual scales of the test. Persons with high level of fanaticism showed significantly higher level of communicative intolerance $(p=0,003)$. They also more often use themselves as a standard when assessing the behavior and way of thinking of other people $(p=0,0004)$, try to change, reeducate their partners $(p=0,05)$, try to fit their partners for themselves, to make them "convenient" ( $p=0,0007)$, not able to hide or smooth over their bad feelings when faced with some uncommunicative characteristics of their partners $(p=0,03)$, not able to adapt to the character, habits and desires of others $(p=0,002)$; intolerant to physical or mental discomfort caused by the other people $(0,02)$.

In the sphere of the base convictions the only statistically significant difference between two studied groups was discovered in variable of belief in randomness of events in the world. Persona with high fanaticism to a greater extent share this conviction $(p=0,007)$. People with low fanaticism mostly believe that some predefined order of world events exists.

We found that students with different levels of fanaticism differed in their ability to recognize facial expressions of emotion. Students with high fanaticism in general recognized mimetic emotional expression worse than people with low fanaticism $(p=0,04)$, in particular, significant differences were found in the recognition of fear $(p=0,01)$, disgust $(p=0,01)$, anger $(p=0,05)$, contempt $(p=0,04)$.

In the sphere of self-regulation the only statistically significant difference between two studied groups was discovered in variable of flexibility. Persons with high fanaticism were much less flexible in their activity than persons with low fanaticism $(p=0,003)$.

There were no statistically significant differences between two studied groups in intercultural adaptation, stress overcoming strategies, life meanings orientations, social and emotional intelligence and general tolerance (diagnosing with «Tolerance Index» test).

\section{Finding of correlation analysis}

The types of ethnic identity displayed statistically significant correlations with almost all the studied personality characteristics that define the nature of intercultural interaction, except stress overcoming strategies and intercultural 
adaptation (Yankovsky test). Totally 304 statistically significant correlations were found at the significance level $p \leq 0,05$. Therefore, in this paper we are presenting only correlations of ethnic fanaticism. It should be noted that the variable of ethnic fanaticism found the smallest number of links to personal characteristics, as well as variable of ethnic indifference. All the other ethnic identity types found much more significant correlation with personal characteristics.

High level of fanaticism in interethnic relations demonstrates significant direct correlation with the general level of communicative tolerance, as well as with the same variables, in which significant differences between the groups were found: perceiving themselves as a standard when assessing the behavior and way of thinking of other people $(p=0,0004)$, try to change, reeducate their partners $(p=0,05)$, try to fit their partners for themselves, to make them "convenient" $(p=0$, 0007), not able to hide or smooth over their bad feelings when faced with some uncommunicative characteristics of their partners $(p=0,03)$, not able to adapt to the character, habits and desires of others $(p=0,002)$; intolerant to physical or mental discomfort caused by the other people $(0,02)$.

Also the inverse significant correlation of ethnic fanaticism with ethnic tolerance level was found.

Among the indicators of foreign students intercultural adaptation the sense of alienation showed a direct significant relationship with their fanaticism in intercultural relations. The high level of ethnic bigotry is inversely correlated with the number of social roles provided by representatives of almost all considered ethnic groups except South-East Asia and South America.

In the field of life meaning orientations ethnic fanaticism found significant correlations with the general level of life meaningfulness, with clear understanding of one's goals in life and with internal locus of self - control.

In base convictions ethnic fanaticism found direct correlation with the conviction in random character of the world events in, which once again confirms the above described Mann-Whitney test data. And also correlation of fanaticism with awareness of their own "l" values was discovered.

Although significant correlations of fanaticism with overall levels of social and emotional intelligence have not been identified, there were links to their individual scales. In particular, ethnic bigotry inversely related to the non-verbal expression understanding and understanding of emotions (especially the emotions of others). Correlation analysis also confirmed and supplemented Mann-Whitney test data, finding significant correlations of ethnic bigotry with the general ability to understand the emotions of facial expressions and with abilities to understand almost all emotions, checked by the test, but emotion of joy.

In self-regulation styles U-test data also have been confirmed, significant inverse association of behavior flexibility with fanaticism was detected

Finding of differences in ethnic identity styles between students belonging to different religions

The aim of the next stage of our study was to compare the styles of ethnic identity of students belonging to different religions. We conducted a comparative analysis of three groups: Christians, Muslims and Buddhists. Every religious group included students from different regions of the world. Statistically significant differences between the groups for any variables of ethnic identity were not revealed. Only the trend can be noted that Muslims had somewhat less pronounced positive ethnic identity than the other, and a bit higher level of ethnic isolationism. In levels of ethnic fanaticism these three groups did not differ significantly: average levels in all three groups were similar.

\section{Finding of cross-cultural analysis of ethnic identity styles of Muslim students}

At the next step, we conducted the comparative analysis of ethnic identity of Muslims young persons from two different regions of the world: the Middle East and Central Asia.

The overall ethnic identity profiles of in both groups were similar. In ethnic identity of the students from the Middle East and from Central Asia prevailed positive ethnic identity (12.9 / 15.4 respectively, max =20), all deviations from this type were much less expressed. Among other types most strongly expressed were ethnic indifference ( $9.6 / 10.5)$, followed by ethnic bigotry $(9,2 / 7,9)$, then ethnic isolation $(8,7 / 6,2$ and, ethnic egoism $(8,3 / 5.9)$. Least of all in both groups went ethnic nihilism $(7.0 / 4.8)$. For all of the variables the differences were statistically significant. The most significant differences were in the levels of positive ethnic identity $(p=0,00002)$, ethnic nihilism $(p=0,00007)$ and ethnic fanaticism (bigotry) $(p=$ 0.020 ). For the remaining scales differences were at the level $p=0.05$. 
To better understand the differences in the two groups' ethnic extremism manifestations, we conducted a correlation analysis of all variables of interest for each of the subsamples.

In the group of students from the Middle East, as well as in the total sample were found significant direct links of ethnic bigotry with general communicative intolerance, especially with rejection or misunderstanding of other persons' identity, using oneself as a standard when assessing the behavior and way of thinking of other people, categoricity or conservatism in the estimates of other people; inability to hide or smooth over bad feelings when faced with some uncommunicative characteristics of the partners; desire to fit partners for themselves, to make them "convenient". Here as well as in the total sample fanaticism was associated with a sense of alienation in interpersonal relationships in situations of intercultural communication, and with conviction in randomness of the world events.

In the total sample ethnic bigotry was inversely related to ethnic tolerance, but in this group it was associated with intolerance to different social groups, somehow different from the dominant culture in the society.

Fanaticism's inverse correlation with behavior flexibility revealed in the general sample, in this group didn't reach the level of significance. But here specific for this group inverse correlation of ethnic fanaticism with the ability to simulate future results of activities was detected.

Among the life meaning orientations, as well as in the total group, ethnic bigotry was inversely associated with the clearly perceived goals in life. In the area of basic convictions the correlations differed from general trends. For students from the Middle East ethnic bigotry was inversely related to the belief that life events may be controlled, and it was directly linked with the belief in the people benevolence.

The significant correlations of ethnic bigotry with variables of social intelligence in this group were not found. But there were more than the in the total sample significant inverse links with the various parameters of emotional intelligence, in particular, with interpersonal and intrapersonal emotional intelligence, understanding emotions (primarily of the others) and regulation of emotions (especially one's own).

It is interesting that among the variables of emotions recognition in facial expressions were found only one significant correlation of ethnic bigotry - with the recognition of fear.

In the group of the Central Asian students we discovered less correlations of ethnic fanaticism with communicative intolerance than in total sample. Here it is linked only with using oneself as a standard when assessing the behavior and way of thinking of other people, categoricity or conservatism in the estimates of other people and desire try to change, reeducate their partners.

At the Central Asian students ethnic bigotry inversely correlated with all types of tolerance under consideration (ethnic, social and personal), but mostly - with ethnic one.

In the field of cross-cultural adaptation the level of ethnic fanaticism not only directly correlated with the sense of alienation, as in the total sample and in the Middle East students group, but also inversely correlated with the satisfaction with one's adaptation. But what is particularly interesting in this group high level of ethnic bigotry directly linked to the adaptability, willingness to make an effort to interact with the new culture.

In the regulatory sphere of the Central Asian students ethnic fanaticism was inversely related to the ability to program their own actions. In contrast to the total sample and to the group of Middle East students, at the Central Asian students significant direct connections of ethnic fanaticism with such solving problems styles as searching for social support and avoidance were detected.

In the total sample we saw ethnic fanaticism's inverse correlation with life meaningfulness, and in both above described groups - with the clearly perceived life goals, but in the group of Central Asian students we could see the opposite trend. Here ethnic bigotry was directly linked to the general level of life meaning, and with its individual indicators, such as clearly perceived goals, confidence in one's ability to control own life, focus on the life process, ie desire to enjoy the moment.

Also, along with the common for all the considered groups correlation of fanaticism with conviction in the randomness of the life events, in the group of Central Asian students were found significant direct connections of fanaticism with conviction in the world controllability and one's own luck.

In social intelligence in this group also specific connection of ethnic fanaticism with the capacity for non-verbal expressions evaluation were noted. In emotional intelligence in this group the only significant inverse association of fanaticism with ability to emotions regulation were noted. And, as in the total group, here ethnic fanaticism inversely related to both the general ability to recognize emotions, and in particular - to the ability to recognize almost all the emotion, but joy. 


\section{Discussion}

According to the research data, students with extreme attitude toward other nations more often have deviations in their ethnic identity types, both toward hypoidentity (neglecting ethnicity problems) and toward hyperidentity (increased importance of ethnicity problems). Thus in general their styles of ethnic identity and accordingly styles of intercultural interaction may be determined as controversial. In any case such people prefer to keep a great distance with other nations' representatives. Not surprising that such people feel alienation in a new cultural environment.

These students display intolerance not only in interethnic communication, but as well in interpersonal interaction with representatives of their own nation. They don't accept other people's individuality; have not enough competences for constructive interaction with different people. In relations they take mainly sociocentric position.

Propensity to extremism in relations associated with a number of personality characteristics. Their world view is characterized by the belief in random nature of the world events, by the conviction that man cannot control these events and affect them in any way. Young people with extremist ethnic sets have lower levels of their life meaningfulness. They not so clearly aware their life goals and do not take responsibility for their own lives and personal development.

Young persons with high fanaticism have certain difficulties in communication, in particular, they hardly recognize other people's emotional expression, especially negative emotions, such as fear, disgust, anger, contempt. Also such persons have difficulties with flexible changing their behavior in accordance with the changing circumstances.

Thus, it can be argued that not only ethnic identity style of young people with high ethnic fanaticism is controversial, but their overall style of self-realization in different spheres of life. Important factors of such attitudes are the low level of skills for effective communication and regulation of their own activities, as well as egocentric position in conjunction with the conviction in unpredictability and uncontrollability of the world.

We carried out comparative analyzes of religious and ethnic groups. These analysis showed no statistically significant differences in the styles of ethnic identity among religions, but found significant differences in the severity of all types of ethnic identity. This suggests that the factor of ethnicity plays more important role than the factor of religion. That is, people of different countries belonging to the same religion differ in their styles of intercultural interaction more than the representatives of one religion, living in one country.

The comparative analysis of ethnic identity of Muslims young persons from two different regions of the world ( the Middle East and Central Asia) helped us to reveal not only differences in their levels of ethnic fanaticism, but also ethnic peculiarities in possible mechanisms of ethnic extremism formation.

These comparative analysis showed that students from the Middle East had much more pronounced ethnic bigotry and various deviations of ethnic identity. And students from Central Asia had more pronounced positive ethnic identity. Ethnic fanaticism in these two ethnic groups showed specific ties with personal characteristics.

At the students from the Middle East ethnic bigotry was connected not as much with ethnic intolerance as with social tolerance, ie rejection characteristics of different social groups. Also fanaticism of these students was associated with low ability for modeling future outcomes of one's activities, with difficulty in understanding the others' emotions and in regulating one's own emotions. In addition, their ethnic bigotry is directly related to conviction in the people benevolence. Summarizing these data, we can assume that extremism in interethnic relations of Middle Eastern students associated with difficulties in achieving their goals in their activity and communication, with their tendency to rely on other people. In other cultures surrounding, naturally, it is not so easy to find people they can rely on (considering the communication difficulties), all that apparently cause some tension and the desire to oppose their own and others' ethnic groups.

At the Central Asian students' group ethnic bigotry to a lesser extent related to the general communicative intolerance, but it is more related to the general ethnic intolerance. That is, possibly, ethnic bigotry of Central Asia representatives has less to do with the general attitude of the people, but and only applies to situations of interethnic interaction. This is confirmed by the inverse correlation of fanaticism with cross-cultural adaptation satisfaction. That is, perhaps, ethnic bigotry in this group can be regarded as a consequence of unsuccessful intercultural adaptation.

In addition, our findings suggest that the lack of success in adaptation in this group, in turn, is associated with poor ability to program its activities, with a tendency to avoid problems or to seek help of others. Apparently, the Central Asian students who are prone to extremism in interethnic relations, in contrast to other, are well aware of their goals in life, confident in their abilities, but have difficulties in deliberate and systematic activities aimed at achieving these goals, as more focused on the process than the outcome. This is confirmed by detected inverse correlations of fanaticism with ability to control their own emotions. 
Thus, we can draw the following conclusions:

Generally ethnic extremism correlates with rather controversial and conflict styles of self-realization.

Young people with extreme attitude toward other nations clearly realize their life goals, but they don't believe in the goals approachability, don't have enough abilities to interact with other people, feel certain level of apartness in personal interaction.

Interethnic communication styles of representatives of different Muslim nations have some common features with the other nations, and - some specific features:

Central Asian young people more often show acceptance of their own and other people ethnicity and individuality.

The Arab youth ethnic extremism correlates mostly with social stereotypes and hostility to other social groups. Central Asian youth extremism correlates with intolerance to the other people individuality manifestation.

Psychological factors of Arab young people extremism are low life meaningfulness, absence of clear life goals, conviction in unpredictable and uncontrollable world, in the people's benevolence and the desire to rely on others in setting and achieving their life goals. For Central Asian young people psychological factors of extremism are contradictions between clear understanding of their life goals and their low ability for systematic efforts to achieve these goals. For both groups important factor of ethnic extremism is low communicative competences, especially understanding the other people's emotions and regulation of their own emotions.

Personal resources for the ethnic extremism reduction could be: for Arab people - their self - control in emotions and activity; for the Central Asian people - concentration on their life goals. Positive and strong social support may help all to feel important and valued, to understand their life goals and values better, to feel less lonely and isolated, to have higher self confidence and self-esteem, to understand other people better, to develop their social competences.

\section{References}

Bezmenov, I.V. \& Belovol, E.V. (2007) Diagnostica individualnyh osobennostey socialnoy percepcii: practicum po discipline "Psyhologiya socialnogo poznania". (Diagnosis of individual characteristics of social perception: practical work on the subject "The Psychology of Social Cognition."). Moscow: RGSU Publishing "Sojuz".

Berry, J.W. (1997) Immigration, acculturation and adaptation. IApplied psychology: An international review, 46(1), 5 - 34. Burlarchik, L.F. \& Morozov, S.M. (1999) Slovar - spravochnik po psyhodiagnistike. (Dictionary of psychodiagnosis), StPetersburg: Piter.

Cesari, J. (2002) Islam in France : the shaping of a religious minority. In Haddad-Yazbek, J. (Ed.) Muslims in the West, from Sojourners to Citizens, Oxford University Press, 36-51

Chebotareva, E. (2012) Intercultural adaptation to Russia of students from Asia, Africa, Latin America and the Middle East. Bulletin of the Peoples' Friendship University of Russia. Series: Psychology and Pedagogics, 3, 6-11.

Chebotareva, E.Ju. (2012) Strategies of Overcoming Acculturation Stress in Students from Different Parts of the World. Bulletin of the Peoples' Friendship University of Russia. Series: Psychology and Pedagogics, 1, 42-49.

Chebotareva, E.Ju. \& Shkvarilo, K.A. (2012) Personal Factors of Ethnic Tension among Russian Multinational University First Year Students. Behavioral, Cognitive and Psychological Sciences III / International Proceedings of Economics Development and Research. IACSIT Press, Singapore, 53, 5-9.

Chebotareva, E. (2014) The role of personal self-realization styles in cross-cultural communication. Proceedings and abstracts of the 85th annual meeting of the Eastern psychological association, Boston, MA.

Chebotareva, E. (2014) Multi-dimensional and functional approach to the intercultural adaptation study. Journal of Educational and Social Research, .4 (2), 170-174.

Franz, B. (2007) Europe's Muslim Youth: An Inquiry into the Politics of Discrimination, Relative Deprivation, and Identity Formation. Mediterranean Quarterly, 18 (1), 89-112.

Leontiev, D.A. (2000) Test cmyslozhisnennyh orientacyi (SZHO) (Test of the Life Meanings Orientations), Moscow: Smysl. Lusin D.V. \& Ushakov, D.V. (Ed.) (2004) Socialnyi intellect: teoria, izmerenie, issledovania. (Social Intelligence: Theory, measurement, research), Moscow: "Institut Psychologii" Publishing. 
Mcdonald, L.Z. (2011) Securing Identities, Resisting Terror: Muslim Youth Work in the UK and its Implications for Security. Religion, State and Society, 39 (2-3), 177-189.

Morosanova, V.I. (2004) Stil samoregulyatsii povedenia. (Style of behavior self-regulation), Moscow: SSPM, 15-25.

Mythen, G., Walklate, S. \& Khan, F. (2009) 'I'm a Muslim, but I'm not a Terrorist': Victimization, Risky Identities and the Performance of Safety. The British Journal of Criminology, 49 (6), 736-754.

Novikova, I.A. \& Ibadova T.I. (2009) The problem of a comprehensive study of the tolerance subject. Bulletin of the Peoples' Friendship University of Russia. Series: Psychology and Pedagogics, 4, 25-30.

Novikova, I.A. (2010) Correlation of the tolerance and intercultural adaptation parameters at students from different regions. Bulletin of the Peoples' Friendship University of Russia. Series: Psychology and Pedagogics, 4, 24-28.

Pochebut, L.G. (2005) Vzaimoponimanie kultur: metodologia I metody etnicheskoy kross-kulturnoy psihologii. (Crosscultural understanding: methodology and methods of cross-cultural ethnopsychology), St-Petersburg: St-Petersburg University Publishing.

Saressalo, L. (1977) Folklore ja etninen identiteetti (Folklore and ethnic identity). In Ahlberg, N. (Ed.). Kulttuuri-identiteetin ongelmia: Suomalaiset kulttuurivahemmistot. (Culture, identity problems: Finnish cultural minorities.) Report for the Finnish National Commission for UNESCO seminar on Cultural identity and cultural pluralism. Finnish National Commission for UNESCO Publication Series No. 14, Helsinki.

Soldatova, G.U. (1998) Psychologia meshetnicheskoy napryashennosti (Psychology of the interethnic tension), Moscow: Smysl, 40-63.

Soldatova, G.U. \& Shaygerova, L.A. (Ed.), (2003) Practicum po psyhodiagnostike I issledovaniu tolerantnosti lichnosti (Practical work on psycho-diagnostics and tolerance study of personality), Moscow: Moscow State University.

Soldatova G.U. \& Shaygerova L.A. (Ed.) (2008) Psyhodiagnostica tolerantnosti lichnosty.( Psychodiagnostics of the person's tolerance), Moscow: Smysl. 46-50.

Sonin, V.A. (2004) Psyhodiagnosticheskoye poznanie professionalnoy deyatelnosty. (Psychodiagnostic conition of professional activity). St-Petersburg, 206-211.

Stefanenko, T.G. (2006) Etnopsyhologia: practicum (Ethnopsychology: practical work), Moscow: Aspect-press, 66-83.

Sumner W.G. (1906) Folkways. A Study of the Sociological Importance of Usages, Manners, Customs, Mores and Morals. - Ginn and Co.

Yaltonsky V.M. \& Sirota N.A. (1996) Analiz sovremennyh podhodov k profilaktike upotreblenia narkotikov. (Analysis of current approaches to drug prevention). Voprosy narcologyi (lissues of addiction), 3. 91-97. 